\title{
B. Bolduc, La Fête imprimée. Spectacles et cérémonies politiques (1549-1662)
}

\section{Maurizio Busca}

\section{Q OpenEdition \\ 1 Journals}

\section{Edizione digitale}

URL: http://journals.openedition.org/studifrancesi/9929

DOI: 10.4000/studifrancesi.9929

ISSN: 2421-5856

\section{Editore}

Rosenberg \& Sellier

\section{Edizione cartacea}

Data di pubblicazione: 1 août 2017

Paginazione: 351-352

ISSN: 0039-2944

\section{Notizia bibliografica digitale}

Maurizio Busca, «B. Bolduc, La Fête imprimée. Spectacles et cérémonies politiques (1549-1662)», Studi Francesi [Online], 182 (LXI | II) | 2017, online dal 01 août 2017, consultato il 06 janvier 2021. URL: http:// journals.openedition.org/studifrancesi/9929; DOI: https://doi.org/10.4000/studifrancesi.9929

Questo documento è stato generato automaticamente il 6 janvier 2021.

\section{(c) $(1) \&$}

Studi Francesi è distribuita con Licenza Creative Commons Attribuzione - Non commerciale - Non opere derivate 4.0 Internazionale. 


\title{
B. Bolduc, La Fête imprimée. Spectacles et cérémonies politiques (1549-1662)
}

\author{
Maurizio Busca
}

\section{NOTIZIA}

BENOÎT BOLDUC, La Fête imprimée. Spectacles et cérémonies politiques (1549-1662), Paris, Classiques Garnier, 2016, 392 pp.

1 Il volume propone lo studio dei livres de fête pubblicati per commemorare cinque grandi celebrazioni pubbliche che hanno avuto luogo a Parigi fra la metà del Cinquecento e la metà del secolo successivo: l'entrée di Henri II e Caterina de' Medici a Parigi (1549), il Balet comique de la Royne (1581), gli spettacoli equestri dei Chevaliers de la Gloire organizzati in occasione della promessa di nozze di Louis XIII (1612), l'inaugurazione della sala degli spettacoli del Palais Cardinal (1641) e l'entrée di Louis XIV e di MarieThérèse d'Autriche a Parigi (1660). All'interno del ricchissimo panorama delle relazioni di festeggiamenti pubblici cinque e secenteschi, l'A. seleziona cinque eventi di carattere dinastico e/o politico che permettono di osservare la costituzione e l'evoluzione del genere del livre de fête e, al contempo, di misurare le peculiarità dei singoli testi in virtù delle occasioni particolari di composizione, dei destinatari privilegiati cui si rivolgono e delle pratiche editoriali adottate. La questione del pubblico supposto di tali opere è oggetto di attenzioni particolari dell'A.: i livres de fête non sono dei testi documentari, e attraverso lo studio delle vicende editoriali, delle strategie compositive, della scelta delle illustrazioni e dell'organizzazione della materia sulla pagina è possibile chiarire gli interessi che soggiaciono alla loro produzione.

2 I festeggiamenti per l'entrée di Henri II a Parigi, la cui organizzazione viene affidata a Jean Martin e Thomas Sébillet, sono relati in diverse opere a stampa. Il testo ufficiale è caratterizzato da un'inedita attenzione per le costruzioni effimere erette per accogliere il re nella sua capitale, descritte minuziosamente (il modello stilistico è Vitruvio) e rappresentate nella maggior parte delle illustrazioni che impreziosiscono il volume - le 
quali, peraltro, si imporranno come modelli per le entrées che saranno pubblicate in seguito - in una celebrazione della figura reale e allo stesso tempo della città di Parigi. Ben altra funzione viene riconosciuta al Balet de la Royne, dedicato ai festeggiamenti per il matrimonio del favorito duca di Joyeuse con Marguerite de Lorraine. L'A. considera il libello, infatti, come una «opération de relations publiques» (p. 102) tesa a celebrare non tanto un riavvicinamento alla famiglia di Guise, quanto una nuova stabilità politica raggiunta col conferimento di elevati poteri a cortigiani anti-ligueurs. Per quanto riguarda la terza manifestazione presa in esame, il grande carrousel che ebbe luogo nella Place Royale il 5-7 aprile 1612, sono due i libri commemorativi apparsi all'indomani dell'evento e ufficialmente riconosciuti dall'autorità reale (accanto a numerose pubblicazioni non ufficiali): il Camp de la Place Royalle, che si vuole testimone della «pure vérité» dei fatti, e il Romant des Chevaliers de la Gloire, che inserisce il carrousel in una cornice narrativa e ne contamina la relazione con episodi romanzeschi inventati. Entrambi i libri riuniscono una cospicua mole di materiali eterogenei (descrizioni, liste di partecipanti, raccolte di devises, testi circolati durante l'evento) che, a giudizio dell'A., trovano la sistemazione più efficace nel secondo: la cornice, per quanto fittizia, assicura un'unità narrativa e guida il lettore nella decodificazione del dispositivo figurativo, esaltando «la vérité non de l'histoire, mais de toute une tradition chevaleresque» (p. 189). Il quarto evento, l'inaugurazione della sala degli spettacoli del Palais Cardinal, rappresenta per Richelieu l'occasione di affermare la dignità della pratica teatrale cittadina accordandole il prestigio fino ad allora riconosciuto agli spettacoli di corte. La pièce scelta per l'ouverture è la tragicommedia Mirame di Desmarets (modello di teatro normativo promosso dal Cardinale), che viene stampata in un'edizione di pregio (un in-folio ornato di sei stampe) avente il doppio scopo di restituire il testo teatrale e di commemorare l'evento, e assimilabile sotto più aspetti alla categoria dei livres de fête. L'ultima cerimonia studiata, l'entrée della giovane coppia reale a Parigi, è relata in un volume apparso due anni dopo i festeggiamenti del 1660. Si sottolinea l'originalità del trattamento delle illustrazioni, dalle quali emerge un inedito dinamismo che partecipa degli intenti del progetto editoriale (l'osservanza dei principi di exactitude, fidélité e dignité) e che rompe con la staticità impostasi un secolo prima con l'ingresso di Henri II a Parigi. Una continuità è tuttavia riscontrabile negli intenti dei relatori delle due entrées royales: «la cérémonie d'entrée, préparée par la ville, confirme autant le pouvoir de ses institutions que l'autorité du souverain; elle relève dans le détail des rapports hiérarchiques et traduit l'importance des figures de l'autorité civile aussi bien que royale» (p. 238). Completano il volume una sezione di annexes e illustrazioni (pp. 293-348), bibliografia e indici. 